\title{
Bolchevismo ou maximalismo: uma abordagem terminológica e diacrônica ${ }^{15}$
}

\section{Bolchevismo or maximalismo: a terminological and diachronic approach}

\author{
Fabiana Zogbi Lontra da Conceição*
}

\begin{abstract}
RESUMO: Este trabalho tem como objetivo descrever e analisar o emprego do termo bolchevismo e de suas variantes no momento de sua introdução e início de sua circulação no Brasil (1917-1920). Para tanto, adotamos a ótica da Terminologia Diacrônica em conjunto com a Socioterminologia Variacionista. Utilizamos como fonte os registros jornalísticos reunidos em $O$ Ano Vermelho (MONIZ BANDEIRA; MELO; ANDRADE, 1980) e o acervo de jornais da Hemeroteca Digital Brasileira com o intuito de verificar em que categorias de variantes do constructo de Faulstich (2001) os termos se inserem. Através da análise das variantes, concluímos que a variação, de ordem competitiva, foi suprimida pela necessidade de definição do conceito, o que levou à consagração do termo bolchevismo.
\end{abstract}

PALAVRAS-CHAVE: Terminologia Diacrônica; Socioterminologia; bolchevismo; maximalismo.

ABSTRACT: This work describes and analyses the use of the term "bolchevismo" and its variants at the moment of its introduction and circulation in Brazil (1917-1920). The theories used are those of Diachronic Terminology and Sociotherminology. As sources, we use the journalistic archives gathered in $O$ Ano Vermelho (MONIZ BANDEIRA; MELO; ANDRADE, 1980) and the newspaper collection from Hemeroteca Digital Brasileira in order to verify in which categories of variants of the Faulstich construct (2001) the terms may be inserted. Our analysis leads to the conclusion that the variation, of a competitive type, was suppressed by the need to define the concept, which led to the preference of the term "bolchevismo".

KEYWORDS: Diachronic Terminology; Socioterminology; bolchevismo; maximalismo.

15 O presente trabalho foi realizado com apoio da Coordenação de Aperfeiçoamento de Pessoal de Nível Superior - Brasil (CAPES) - Código de Financiamento o01.

* Mestranda em Estudos da Linguagem pela Universidade Federal do Rio Grande do Sul, bacharela em Letras pela mesma universidade, bolsista da CAPES, fablontra@gmail.com, ORCID oooo-0001-7807-3275. 
A memória histórica da humanidade está repleta desses signos ideológicos mortos, incapazes de serem palco de interesses sociais vivos. No entanto, uma vez que o filólogo e o historiador se lembram dos signos, estes ainda preservam os últimos sinais vitais. (VOLÓCHINOV, 2019, p. 319)

\section{Introdução}

Este trabalho dá continuidade à nossa trajetória de pesquisa sobre a terminologia política de contexto russo-soviético empregada no Brasil, iniciada na monografia $O$ discurso leninista (1902-1918): levantamento terminológico (LONTRA DA CONCEIÇÃO, 2019), em que realizamos um levantamento terminológico a partir de um corpus de traduções de textos de Vladímir Lênin para o português brasileiro, com o intuito de identificar o que seria uma terminologia da Revolução Russa na nossa língua. Neste momento, o foco é exclusivamente no termo bolchevismo e suas variantes em seus primeiros anos de circulação no Brasil, uma vez que tal termo possui relevante importância na história mundial. Nosso objetivo é, portanto, descrever e analisar os primeiros anos de circulação do termo e suas diversas variantes, a partir do gênero jornalístico, para compreender como este fenômeno histórico e político foi recebido, traduzido e incorporado no Brasil. Para tanto, adotamos as perspectivas da Terminologia Diacrônica e da Socioterminologia com o intuito de avaliar o termo bolchevismo e suas variantes em uma perspectiva linguística, terminológica e diacrônica. Tal ótica justifica-se uma vez que estudos sobre o mesmo tema foram realizados em uma perspectiva unicamente histórica. Aqui, tratando de terminologia, entendemos por termo um elemento lexical especializado com função comunicativa e valor social e cultural, a partir das premissas de Faulstich (1998, p. 9, grifos da autora, tradução nossa): “um conceito é uma unidade de conhecimento que contém os atributos de um determinado referente, chamado termo"16.

16 "un concept est une unité de connaissance qui contient les attributs d'un certain référent, 
Começamos o artigo situando o termo bolchevismo em seu contexto de criação na Rússia e sua chegada ao Brasil, apoiando-nos principalmente em Weill (1975), Moniz Bandeira, Melo e Andrade (1980) e Bartz (2016). Em nossa fundamentação teórica, realizamos uma breve revisão bibliográfica dos estudos em Terminologia Diacrônica em contexto internacional e nacional, visto que tal ramo de pesquisa ainda é pouco explorado dentro dos estudos de Terminologia; apresentamos alguns conceitos básicos da Socioterminologia a partir de Gaudin (1993; 2007) e, em seguida, passamos à Socioterminologia Variacionista sistematizada por Faulstich (2001).

Em Materiais e Métodos, apresentamos mais detidamente o livro O Ano Vermelho: a revolução russa e seus reflexos no Brasil (MONIZ BANDEIRA; MELO; ANDRADE, 1980), principal fonte para nossa pesquisa, que foi complementada pelo acervo da Hemeroteca Digital Brasileira (BNDIGITAL, 2020), e descrevemos nossa metodologia de análise, pautada nas classificações de variação apresentadas por Faulstich (2001). Passamos, finalmente, à descrição e análise de nosso material, momento em que identificamos os tipos de variantes e o processo de apagamento e consagração de determinadas variantes.

\section{O bolchevismo: da Rússia ao Brasil}

A origem do termo bolchevizm (большевизм) remonta ao congresso de refundação do Partido Operário Social-Democrata Russo (POSDR), ocorrido em 1903, época de forte agitação política na Rússia - lembremos que já em 1905 aconteceria uma primeira revolução russa, considerada por muitos historiadores um “ensaio geral” da Revolução de 1917 (REIS FILHO, 2017). Durante o congresso, dois grupos opostos apresentaram divergências insuperáveis: o grupo representado por Vladímir Lênin ${ }^{17}$ propunha uma organização partidária de

\footnotetext{
appelé terme".

17 Vladímir Lênin (1870-1924) foi um revolucionário, líder dos bolcheviques e um dos principais articuladores da Revolução Russa de 1917.
} 
militantes profissionais; o grupo em torno de Julius Martov ${ }^{18}$, por sua vez, defendia um partido sem restrições de filiações. A proposta de Martov, ao entrar em votação, foi a vencedora. Porém, quando o Congresso passou à decisão sobre a composição da direção e do corpo editorial do Iskra, o jornal do partido, alguns delegados retiraram-se do plenário. Assim, ainda que com o mesmo número de votos, o grupo liderado por Lênin venceu a votação, sendo considerado a maioria (bolchinstvó, большинство, em russo), enquanto o grupo de Martov passou a ser considerado a minoria (menchinstvó, меньшинство). A historiadora Claudie Weill (1975), em seu artigo À propos du terme "bolchevisme”, comenta que, até o fim de 1904, as duas frações preferiam utilizar os termos leninistas e martovistas para designar uma à outra, ou simplesmente "maioria" e "minoria", frequentemente com aspas. Segundo a autora, "a ausência de uma denominação clara é a marca da não aceitação da cisão ou, ao menos, do fato de que ela não foi percebida desse modo"19 (WEILL, 1975, p. 354, tradução nossa).

No entanto, termos onomásticos, como leninismo, estavam um tanto ultrapassados na virada do século XX. Com a ascensão da social-democracia, movimento internacional de grande importância para a política europeia ao qual o próprio POSDR filiava-se, termos mais genéricos tornaram-se a tendência para designar grupos políticos, como revisionismo ou reformismo. O motivo, talvez, fosse superar a associação de grupos políticos a um só dirigente ou pensador. Possivelmente por isso, Lênin nega a designação a partir de seu nome e passa a empregar bolchevique e menchevique, com aspas, em cartas a partir de 1904. Já os mencheviques, ainda que relutantes em aceitar a designação que lhes renderia um lugar na história, passam a utilizar os termos bolchevique e menchevique ao fim de 1905 (WEILL, 1975). Na verdade, segundo Weill (1975), a dinamicidade das disputas internas do partido era um fator importante para que a terminologia fosse fixada. O nível de unidade ou de cisão no interior do POSDR refletia-se na

\footnotetext{
${ }^{18}$ Julius Martov (1873-1923) foi fundador, ao lado de Lênin e de outros revolucionários, da União de Luta pela emancipação da classe operária (1895) e do POSDR. Com a cisão do POSDR, tornase dirigente da fração menchevique.

19 "L'absence de dénomination nette est la marque d'une non-acceptation de la scission ou, du moins, du fait qu'elle n'est pas perçue comme telle".
} 
escolha lexical em documentos e atas: em determinados momentos, bolchevismo e menchevismo desaparecem, dando lugar a "maioria" e "minoria".

Em 1913, Lênin escreve um artigo enciclopédico sobre o bolchevismo, sem fornecer uma definição propriamente dita. Em vez disso, prefere traçar um percurso histórico do grupo, relatando a cisão do POSDR. Dessa maneira, Lênin tentava fixar o bolchevismo como uma tradição, uma história a ser reivindicada, e ele seria o guardião dessa tradição. A estratégia de narrativa, como a história demonstra, parece ter dado certo. Até 1917, o bolchevizm, ao menos na língua russa, tornar-se-ia a designação consagrada até os dias de hoje. Entretanto, tendo em vista o caminho acidentado pelo qual esse termo passou, é fácil compreender a dificuldade que sua tradução traria para o nosso país. Vejamos, portanto, como o bolchevismo chegou ao Brasil.

Moniz Bandeira, Melo e Andrade (1980), em seu livro O Ano Vermelho, reúnem uma série de documentos históricos que retratam o recebimento da Revolução Russa no Brasil, desde notícias da imprensa até boletins policiais, passando por diversos documentos de grupos políticos da época. Segundo os autores, no começo do século XX, os brasileiros já se interessavam bastante pela literatura e política russas. Era comum discutir-se autores russos na intelectualidade e na vanguarda operária, esta última profundamente dominada pelas ideias anarquistas. Em 1904, em São Paulo, formou-se um movimento de solidariedade ao povo russo. Criou-se uma Comissão Pró-Mártires da Rússia, que publicou um manifesto homônimo, redigido em italiano e português. Em 1917, as notícias da Rússia, sempre trazidas pelas mãos de grandes agências internacionais, pipocaram pelos jornais, impactando fortemente os brasileiros. A sede por informações, ligada à escassez de fontes jornalísticas, afora as que representavam países que estavam em guerra com a própria Rússia, levava a todo tipo de notícia falsa: "O nome de Lênin começou a aparecer no noticiário, de abril em diante, como 'espião alemão', 'agente do Kaiser' e 'vendido aos Impérios Centrais"' (MONIZ BANDEIRA; MELO; ANDRADE, 1980, p. 88). Lênin, que só morreria em 1924, foi anunciado morto diversas vezes no ano de 1917: o jornal 
Correio da Manhã chegou mesmo a anunciar que Lênin havia sido substituído por um sósia.

Na época, a exemplo da dificuldade de fixar o termo bolchevismo entre a comunidade política na própria Rússia, as designações para o grupo que tomara a Rússia de assalto também pululavam de todas as formas nos jornais brasileiros: maximalismo, até então, era o termo mais utilizado nas dezenas de notícias reunidas pelos autores em $O$ Ano Vermelho, como na manchete do jornal ANoite, de 8 de novembro de 1917: “Os maximalistas senhores de Petrogrado” (MONIZ BANDEIRA; MELO; ANDRADE, 1980, p. 101). Como tentativa de explicação do termo, o jornal $A$ Razão tentou ligá-lo a Maxim Gorki, cujo nome, na época, era traduzido para "Máximo", que seria a origem, portanto, de maximalismo. Analogicamente, os mencheviques eram chamados de minimalistas nos jornais brasileiros no mesmo período. A respeito da dificuldade de compreensão dos termos relacionados à Revolução Russa, os autores comentam:

\footnotetext{
Faltava, na verdade, a todos, inclusive à intelectualidade, a informação exata e precisa sobre o tipo de regime que, na Rússia, se implantava. Chamavam os bolcheviques de "maximalistas", porque - assim entendiam - apregoavam um programa radical, o programa máximo. Ignoravam que o Partido Operário Social-Democrata Russo se cindira, em 1903, em bolcheviques e mencheviques, por causa da definição de militante e, consequentemente, do conceito de partido. (MONIZ BANDEIRA; MELO; ANDRADE, 1980, p. 145)
}

Recentemente, a problemática em torno do termo maximalismo foi abordada pelo historiador Frederico Bartz (2016), no artigo O maximalismo como problema: circulação e apropriação da ideia de bolchevismo no movimento operário brasileiro durante os primeiros anos da Revolução Russa. Para esse autor, "o termo maximalismo não pode ser visto apenas como uma interpretação enganosa ou má tradução” (BARTZ, 2016, p. 235), uma vez que o próprio conceito gerou debates a respeito das concepções de revolução por parte dos trabalhadores organizados politicamente.

Assim, Bartz (2016), apoiado também em Moniz Bandeira, Melo e Andrade (1980), aborda a questão do ponto de vista da recepção do termo por parte da 
vanguarda operária brasileira, majoritariamente anarquista, que o absorveu de distintas maneiras:

De qualquer forma, durante este período inicial de circulação das referências ao maximalismo e ao bolchevismo entre os militantes brasileiros, existia ainda a possibilidade de identificação, apropriação e reinterpretação destes termos, de uma forma muito mais livre do que seria possível posteriormente. Tendo visto que o maximalismo havia surgido no horizonte como grande referência revolucionária, é necessário compreender também o que era ser maximalista neste momento, ou seja, como eram feitas as apropriações deste termo pelos militantes. (BARTZ, 2016, p. 242-243)

Há, ainda, mais uma questão em torno do termo maximalismo: ele também poderia equivaler ao termo russo makssimalizm [максимализм], que, por sua vez, refere-se a outro grupo político que não o bolchevique. O dicionário Houaiss (2009, s./p.) leva em consideração essa outra acepção do termo no verbete maximalista:

maximalista Datação: 1913 [...]. Rubrica: história da política. 1 relativo a ou partidário do maximalismo; 2 diz-se de ou membro de uma facção dissidente do Partido Socialista Revolucionário, ligado ao movimento camponês russo, que, às vésperas da fracassada Revolução Russa de 1905, exigia a aplicação máxima do programa socialista, mas que em pouco tempo se tornou um insignificante grupo de camponeses anarquistas; 3 uso impróprio: bolchevique. Etimologia ing. maximalist 'id.' e, este, do rus. maksimalíst.

O verbete de Houaiss (2009) traz-nos a informação histórica deste pequeno grupo russo que, no Brasil, poderia gerar bastante confusão devido à polissemia da palavra. Tendo em mente mais esse fator, salientamos que não será nosso interesse aqui desenvolver a discussão a partir do suporte lexicográfico, embora este possa trazer informações interessantes sobre o tema a ser discutido. Uma vez que a questão terminológica em torno do bolchevismo foi tratada por historiadores, tanto na França, por Weill (1975), quanto no Brasil, por Bartz (2016), nosso objetivo é fazer uma abordagem do mesmo tema, dessa vez do ponto de vista linguístico, apoiada nos estudos de Terminologia Diacrônica e Socioterminologia. Assim, de maneira transdisciplinar, poderemos chegar a uma visão mais global a respeito da temática. 


\section{Fundamentação teórica}

\subsection{Terminologia Diacrônica}

Estudos em Terminologia Diacrônica começam a aparecer, segundo Dury e Picton (2009), a partir dos anos 1990, inaugurados provavelmente pelo colóquio de Terminologia Diacrônica ocorrido em Bruxelas, em março de 1988 (HERMANS, 1991). Esses mais de trinta anos, contudo, não parecem ter sido suficientes para que esse ramo de estudo superasse o caráter periférico ao qual foi relegado. Ainda assim, as iniciativas de pesquisa na área da Terminologia Diacrônica apontam resultados frutíferos, demonstrando um vasto campo de estudo ainda pouco explorado. Vejamos alguns exemplos desses estudos.

François Gaudin e Danielle Candel organizaram, em 2006, uma obra consagrada aos estudos diacrônicos, Aspects diachroniques du vocabulaire (CANDEL; GAUDIN, 2006). Os artigos reunidos no livro versam não só sobre terminologia, mas também tradução, lexicografia e semântica. Ressalta-se o artigo de Pierre Auger (2006), Le phénomène de l'anglicisation de la langue forestière au Québec: essai de socioterminologie diachronique, que se insere no campo da Socioterminologia Diacrônica.

Pascaline Dury e Patrick Drouin (2010), interessados em Terminologia Diacrônica e em contraponto aos estudos pautados pelo neologismo, realizam uma pesquisa terminológica na área da Ecologia a partir do conceito de necrologia terminológica. Esse conceito, segundo os autores, diz respeito à obsolescência dos termos e seu desaparecimento no interior das línguas de especialidade, podendo ser subdivido a partir do fenômeno linguístico identificado: necrologia lexical, em que uma forma lexical desaparece da língua; necrologia morfológica, em que desaparecem afixos no interior de uma forma lexical; necrologia gramatical, em que há uma mudança na categoria gramatical do termo; e necrologia semântica, em que um sentido do termo desaparece. 
No Brasil, também encontramos interesse pela diacronia manifestado em diversos estudos terminológicos. Maria da Graça Krieger e Anna Maria Maciel (2001), organizadoras do livro Temas de Terminologia, dedicam uma seção da obra ao tema da Terminologia Diacrônica, em que figuram artigos - relacionados também à Terminografia e Lexicografia - de Krieger, Maciel e Finatto. Em trabalhos de maior fôlego, Ivan de Souza (2007) estuda a terminologia açucareira no Brasil na dissertação Do engenho à usina: estudo diacrônico da terminologia do açúcar, e Sandro Marengo (2016) investiga a terminologia militar em língua portuguesa na tese Variações terminológicas e diacronia: estudo léxico-social de documentos manuscritos militares dos séculos XVIII e XIX. Cristian Macedo (2019) também contribui para área em seu artigo A arte da tradução: um breve exercício de terminologia diacrônica.

Os pesquisadores repertoriados também se apoiam em outras teorias de Terminologia que acolhem estudos diacrônicos. Souza, por exemplo, apoia-se nos estudos da Teoria Comunicativa da Terminologia de Maria Teresa Cabré (1993 apud SOUZA, 2007). Macedo (2019, p. 257), por sua vez, considera que "os estudos de Rita Temmerman são incontornáveis ao se pensar a terminologia diacronicamente”, alicerçando-se, assim, na Teoria Sociocognitiva da Terminologia, que estuda os termos enquanto unidades de compreensão em evolução contínua. Já Marengo (2016) prefere fundamentar sua pesquisa a partir da Socioterminologia Variacionista proposta por Enilde Faulstich para estudar os fenômenos de variação em recorte diacrônico.

Nota-se, portanto, que é possível aliar a Terminologia Diacrônica a outras teorias de maneira a melhor compreender determinado objeto de estudo. Assim, passamos aos estudos de Socioterminologia, pela ótica de François Gaudin (1993; 2007) e Enilde Faulstich (1998; 2001), para aprofundar e complementar nosso suporte teórico. 


\title{
3.2 Socioterminologia
}

A Socioterminologia desenvolve-se a partir dos anos 1980, na seara de estudos terminológicos que buscavam aprofundar-se em certas questões de cunho político e social, que os estudos clássicos de Terminologia, notadamente os da escola de Viena, não poderiam responder (GAUDIN, 2007). A Terminologia, como recupera François Gaudin (2007), descobrira que a língua não muda por decreto, não se submetendo, portanto, imediatamente à normatização, e que fatores de uso, de estratificação social e de polissemia, inerentes à língua, também desempenhavam uma influência crucial nas terminologias. Tais preocupações levaram os estudiosos a considerar outros aspectos, até então minimizados nos estudos de Terminologia, como a história. Faulstich, em 1998, já postulava que os termos são entidades variantes que se manifestam nos planos vertical, horizontal e temporal. Avançando nesse aspecto, Gaudin (2007, p. 34, tradução nossa) comenta que: “o estudo dos termos em sua diacronia está envolvido, em seu aspecto linguístico, com a história das designações de conceitos e, portanto, com a história das ideias"20. Em resenha à tese desse autor, Ieda Alves (2003, p. 231-232) acrescenta:

\begin{abstract}
A natureza dessa disciplina, que a coloca nos limites das ciências da cognição, da tradução, da semântica e da sociolinguística, deve também conduzi-la a preocupar-se com a clareza das conceptualizações e, ainda, a refletir sobre sua gênese. Isso explica por que a história dos termos e a das ideias têm tanto em comum.
\end{abstract}

No aspecto metodológico, a Socioterminologia, para responder às preocupações por ela colocadas, opera de maneira descritiva (GAUDIN, 1993). Marengo (2016, p. 72), ao tratar dos sujeitos que utilizam a terminologia, defende o conceito de "comunidade de prática" em oposição à "comunidade de fala" ${ }^{21}$,

20 "l'étude des termes dans leur diachronie est en prise, sous l'aspect langagier, avec l'histoire des désignations de concepts, donc en fait avec l'histoire des idées".

${ }^{21}$ Para isso, o autor estabelece um diálogo com os estudos sociolinguísticos de Penelope Eckert (MARENGO, 2016). 
uma vez que "estamos tratando de linguagem de especialidade, partilhada e usada em contextos de uma determinada prática social específica”. Assim, vemos que diversos aspectos linguísticos das terminologias, antes ignorados, são colocados em maior relevo no âmbito da Socioterminologia. É o caso também da variação, que assume um papel importante dentro da área.

\title{
3.3 Variação
}

Segundo Boulanger (1991, p. 19, apud FAULSTICH, 2001, p. 19, tradução nossa):

\begin{abstract}
A variação terminológica é tão necessária e evidente quanto a variação lexical ou linguística observada por toda língua fragmentada no tempo, no espaço e na sociedade. Essas variações diacrônicas, diatópicas e diastráticas são a própria essência da socioterminologia. ${ }^{22}$
\end{abstract}

No Brasil, Enilde Faulstich foi pioneira nos estudos em Terminologia Variacionista, utilizando-se, para isso, do referencial teórico da Socioterminologia. De acordo com Marengo (2016, p. 68, grifo do autor), a pesquisa de Faulstich, "principalmente no que concerne à conceituação de alotermo, inaugura um espaço importante na tradição de estudos terminológicos dentro e fora do Brasil". A autora propõe o conceito de alotermo para designar a unidade variante de um termo, uma vez que, "sendo a terminologia um fato de língua, ela acomoda elementos variáveis" (FAULSTICH, 2001, p. 25). Segundo seu constructo teórico de variação em terminologia (FAULSTICH, 2001), as variantes terminológicas podem ser agrupadas em concorrentes, co-ocorrentes e competitivas.

Nesse constructo, a autora postula que as variantes concorrentes são variantes formais organizadas em distribuição complementar, ou seja, elas

\footnotetext{
22 "La variation terminologique est aussi nécessaire et évidente que la variation lexicale ou linguistique observée pour toute langue fragmentée dans le temps, dans l'espace et dans la société. Ces variations diachroniques, diatopiques et diastratiques forment l'essence même de la socioterminologie".
} 
concorrem entre si, mas não ocupam o mesmo espaço. A variantes formais são formas linguísticas ou de registro que correspondem "a uma das alternativas de denominação para um mesmo referente, podendo concorrer num contexto determinado" (FAULSTICH, 2001, p. 26). Entre as variantes terminológicas linguísticas, a autora elenca as fonológicas, as morfológicas, as sintáticas, as lexicais e as gráficas. As variantes terminológicas de registro, caracterizadas por apresentarem a variação no plano horizontal, vertical e temporal, são divididas entre geográficas, de discurso e temporais (FAULSTICH, 2001).

As variantes co-ocorrentes, por sua vez, formam a sinonímia terminológica, já que são denominações distintas para um mesmo referente. De acordo com Faulstich (2001, p. 31), “[e]ntre variantes co-ocorrentes há compatibilidade semântica, uma vez que elas se equivalem no plano do conteúdo”, e, assim, podem co-ocorrer num mesmo contexto.

Por fim, as variantes competitivas envolvem itens lexicais de línguas distintas e formam-se através de empréstimos linguísticos e formas vernaculares. Nesse processo de formação, os itens lexicais passam por intersecções no contexto social da língua recebedora e "se tornam variantes porque provocam o surgimento de uma forma vernacular equivalente, por causa do ambiente linguístico estranho à sua permanência natural” (FAULSTICH, 2001, p. 33). O empréstimo, desse modo, motiva o surgimento de um elemento lexical competitivo na língua recebedora. Esse processo de variação pode resultar em formas estrangeiras, híbridas ou vernaculares, que, em todo caso, mantêm o mesmo significado referencial. Lamberti (1999, apud FAULSTICH, 2001, p. 3435) descreve os possíveis comportamentos das unidades lexicais competitivas no português brasileiro:

a) mantêm a forma tal como na língua estrangeira e geram uma forma linguística no português brasileiro;

b) geram palavras derivadas ou compostas híbridas e motivam o surgimento de novos significados para termos vernaculares já existentes no português;

c) geram unidades terminológicas complexas híbridas e vernaculares;

d) abandonam a forma de origem em favor de decalques na língua portuguesa; 
e) abandonam as formas originais na língua estrangeira e geram formas adaptadas às regras morfofonêmicas do português brasileiro.

\section{Materiais e métodos}

Conduzimos nossa pesquisa a partir, principalmente, de fontes secundárias do gênero jornalístico, reunidas em $O$ Ano Vermelho, de Moniz Bandeira, Melo e Andrade (1980). Nelson Werneck Sodré (1980, p. 9), em prefácio à obra, afirma que se trata "do maior acervo de dados já reunidos em livro, entre nós, a propósito do assunto”. O livro foi publicado pela primeira vez pela editora Civilização Brasileira, em 1967, em lembrança aos 50 anos da Revolução Russa. Luiz Alberto Moniz Bandeira, em parceria com Clóvis Melo e Aristélio Travassos de Andrade, todos jornalistas na época, consultaram o acervo de jornais brasileiros do Arquivo Nacional, o acervo de comunicados diplomáticos do Arquivo do Itamaraty e as coleções particulares de documentos dos militantes Astrojildo Pereira e Edgard Leuenroth para compor a obra (MALDONADO, 2017).

Com a leitura e a verificação de variantes nas amostras de notícias apresentadas no livro, optamos por pesquisar em fontes primárias para obter mais dados sobre o uso das variantes. Para isso, utilizamos as fontes extraídas da Hemeroteca Digital Brasileira (BNDIGITAL, 2020), importante acervo de jornais digitalizados brasileiros. Na ferramenta, é possível realizar uma busca avançada por artigos de jornais e revistas a partir de periódicos, palavras-chave ou intervalos fixos de datas. Assim, pesquisamos as palavras-chave bolchevismo, maximalismo, maximismo, bolcheviquismo, bolchevikismo e bolshevikismo nos intervalos de 1910-1919 e 1920-1929, sem limitação de periódicos.

Para o período de 1910-1919, a ferramenta levantou 2.964 ocorrências de maximalismo nos acervos, 2.710 ocorrências de bolchevismo, 664 de bolshevikismo e 51 de bolchevikismo, 13 de bolcheviquismo e 11 de maximismo. 
No período de 1920-1929, a busca por bolchevismo apresentou 3.441 ocorrências, enquanto maximalismo teve 846, bolshevikismo, 110, bolcheviquismo, 24, bolchevikismo, 21 e maximismo, 25.

Finalmente, nossa metodologia pauta-se na descrição das variantes de bolchevismo verificadas a partir da pesquisa nos materiais acima citados. Em nossa análise, buscamos compreender em que categoria de variantes, conforme o constructo de Faulstich (2001), encaixam-se as variantes verificadas.

\section{Descrição e análise}

A leitura integral do livro $O$ Ano Vermelho levou-nos à identificação das seguintes variantes do termo bolchevismo e bolchevique: maximalismo, maximismo, maximalista, bolcheviquismo (grafado, ainda, como bolshevikismo ou bolchevikismo) bolchevista, bolcheviquista. Também identificamos o uso de leninista, que, como relembra Weill (1975), pode ser considerado, em alguns casos, sinônimo de bolchevique. Dentre essas variantes, maximalismo e maximalista são, sem dúvidas, as mais empregadas nas notícias apresentadas pelos autores do livro. Vejamos um exemplo, publicado originalmente no jornal O Imparcial, em 9 de novembro de 1917: "Petrogrado, 9 - O líder maximalista Lênin esteve hoje no QG do Smolni, onde foi alvo de grandes manifestações de carinho por parte dos soldados" (MONIZ BANDEIRA; MELO; ANDRADE, 1980, p. 102).

Ao longo da leitura, também percebemos frequentes as vezes em que mais de uma variante é empregada no mesmo texto, como evidencia a notícia do jornal A Noite, de 11 de novembro de 1917:

Um despacho de agência radiográfica de Haparanda, que conseguiu escapar à censura bolchevista, anuncia que os cossacos, ajudados pelos minimalistas, estão prestes a dominarem os leninistas, com os quais têm travado batalhas nas ruas da Capital. (MONIZ BANDEIRA; MELO; ANDRADE, 1980, p. 106) 
Inspirados pelo exemplo russo, os militantes brasileiros rapidamente passaram a adotar os termos vindos da revolução para seu contexto social. Em novembro de 1918, um imigrante sírio fundou, em Porto Alegre, uma União Maximalista, que, mais tarde, participaria da fundação do Partido Comunista Brasileiro. O governo brasileiro logo tentou combater essas aspirações, como mostra uma nota da polícia do Rio de Janeiro após uma greve, publicada em 18 de novembro de 1918:

A autoridade pública está lutando com anarquistas, quase todos estrangeiros, que querem implantar o maximalismo entre nós e para homens dessa espécie, bem como para os maus brasileiros que os acompanham, todo o rigor é pouco. (MONIZ BANDEIRA; MELO; ANDRADE, 1980, p. 128)

O interesse dos brasileiros no movimento político russo culminou, em 1919, na publicação da brochura O que é maximismo ou bolchevismo: programa comunista, de Hélio Negro e Edgard Leuenroth (apud BANDEIRA; MELO; ANDRADE, 1980). Os autores transcrevem alguns trechos da brochura: "Maximalismo, Bolcheviquismo, etc. são idiotismos que tiveram origem na tradução do idioma russo para o inglês e deste para o português" (BANDEIRA; MELO; ANDRADE, 1980, p. 145, grifos dos autores).

Percebendo o uso das variantes nas notícias reunidas n'O Ano Vermelho a partir de 1917, realizamos, a título de curiosidade, buscas de ocorrências de maximalismo, maximismo, bolchevismo, bolcheviquismo, bolchevikismo e bolshevikismo na ferramenta de pesquisa da Hemeroteca Digital Brasileira (BNDIGITAL, 2020), como apontamos em nossa seção de Materiais e Métodos. Os dados levantados demonstram a preferência de uso pelos jornais do termo maximalismo no período entre 1910-1919. Entretanto, a passagem para 19191929 revela uma preferência por bolchevismo. Apresentamos os dados obtidos pela ferramenta na tabela a seguir: 
Tabela 1 - Ocorrência das variantes no acervo da Hemeroteca Digital Brasileira

\begin{tabular}{ccc} 
& \multicolumn{2}{c}{ Período } \\
\hline Variante & $\mathbf{1 9 1 0 - 1 9 1 9}$ & $\mathbf{1 9 2 0 - 1 9 2 9}$ \\
maximalismo & 2.964 & 846 \\
bolchevismo & 2.710 & 3.441 \\
bolshevikismo & 664 & 110 \\
bolchevikismo & 51 & 21 \\
bolcheviquismo & 13 & 24 \\
maximismo & 11 & 21 \\
\hline \multicolumn{2}{c}{ Fonte: Elaborada pela autora (2020). }
\end{tabular}

Ao observar a brusca queda do uso de maximalismo no acervo de jornais entre 1920-1929, nosso primeiro movimento interpretativo foi rememorar a história do período. Ora, em 1919, é fundada a Terceira Internacional Comunista, órgão idealizado por Lênin para liderar a propaganda comunista em escala mundial. Na década de 1920, no Brasil, a influência anarquista no movimento social brasileiro passa a diminuir com a fundação, em 1922, do Partido Comunista Brasileiro, que foi acompanhada de perto pela Internacional (MONIZ BANDEIRA; MELO; ANDRADE, 1980). Cremos, portanto, que tais movimentos políticos tiveram um importante papel no sentido de erradicar variações que pudessem abrir espaço para interpretações.

A assimilação desses dados, com a ressalva de que não privilegiamos em nossa pesquisa o caráter quantitativo, deve levar em consideração alguns fatores: (a) o fluxo de notícias vindas da Rússia, muito grande no período entre 1917-1918, pode ter diminuído com o passar dos anos; (b) o acervo da Hemeroteca corresponde apenas a uma amostra da produção jornalística das épocas pesquisadas; (c) os diversos textos nos jornais do acervo da Hemeroteca também intercalam as variantes em seu interior, como demonstra o artigo de Ruy Barbosa de 12 de novembro de 1918, publicado na Bahia Illustrada: "A Allemanha está-se dissolvendo, como a Russia, no maximalismo, no bolshevikismo, no sovietismo" (BARBOSA, 1918, p. 12). A figura abaixo, extraída de uma página do jornal $A$ 
Noite, também ilustra o uso intercalado das variantes bolshevikismo, bolshevikista e maximalistas como sinonímias:

Figura 1 - Trecho do jornal A Noite (28/12/1918)

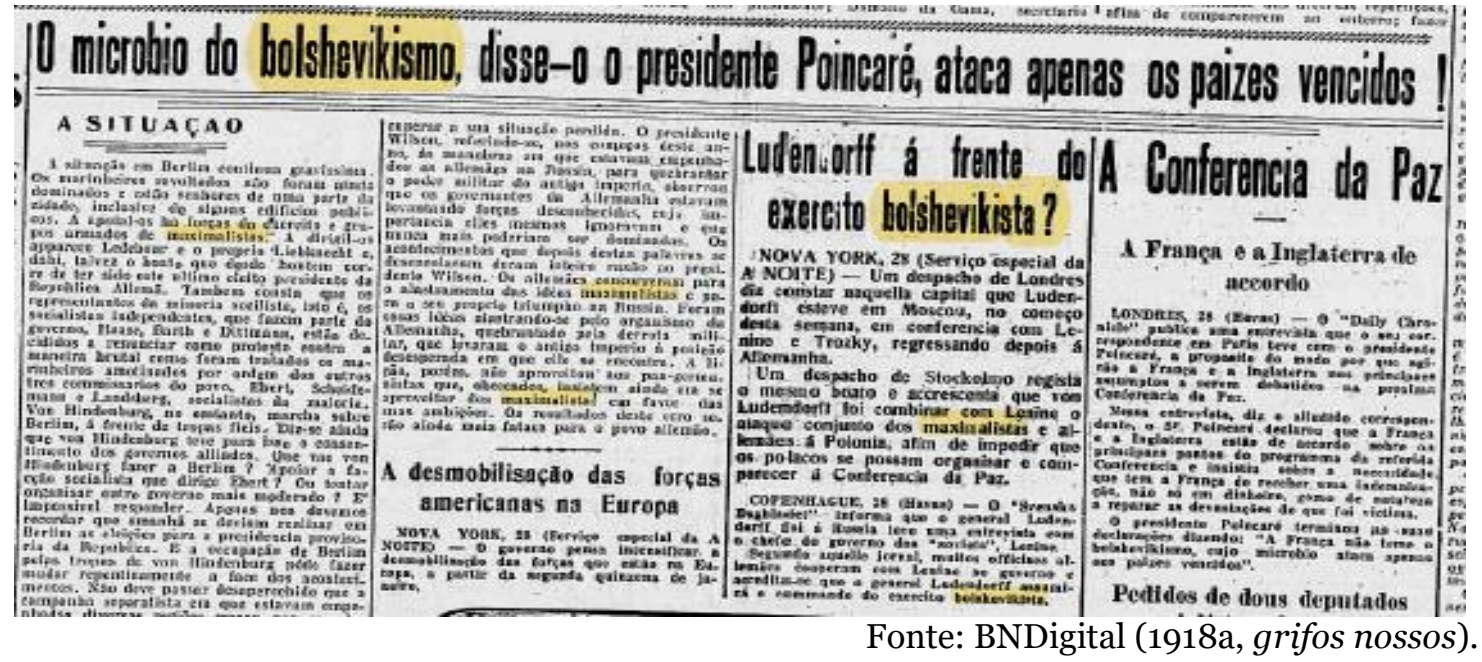

Encontramos, também, em pesquisa na Hemeroteca Digital, ocorrências de bolshevista, bolshevikista, bolcheviquista e bolchevista nos períodos de 19101919 e 1920-1929: "As notícias aqui recebidas da Russia continuam sendo favoraveis ao movimento bolshevista" - Correio Paulistano de 6 de janeiro de 1920) (BNDIGITAL, 1920, s./p.). Encontramos, ainda, algumas ocorrências do termo maximista. Uma das ocorrências é do jornal $O$ Combate, de 7 de janeiro de 1918: "Na Russia, o chefe maximista, sr. Trotsky, declarou que [...] os governos imperiaes russo e allemão haviam firmado um accordo no sentido de combaterem conjunctamente o socialismo [...]” (BNDIGITAL, 1918b, s./p.).

Chegamos, portanto, à seguinte lista de variantes encontradas em nossa pesquisa:

Quadro 1 - Variantes identificadas

\begin{tabular}{|c|c|c|c|}
\hline Maximalismo & maximalista & bolchevismo & bolchevique \\
\hline Maximismo & maximista & bolshevikismo & bolchevista \\
\hline & & bolchevikismo & bolshevista \\
\hline
\end{tabular}




\begin{tabular}{|c|c|}
\hline bolcheviquismo & bolshevikista \\
\hline \multirow{2}{*}{ Fonte: Elaborado pela autora (2020). } & bolcheviquista \\
\cline { 2 - 2 }
\end{tabular}

A homogeneização do termo, uma vez que as notícias proviam majoritariamente das mesmas fontes - as agências de notícias internacionais -, parecia ser o caminho mais natural. Contudo, uma das características mais evidentes nos textos encontrados, seja d'O Ano Vermelho, seja do acervo da Hemeroteca Digital, é o uso intercalado de mais de uma variante na redação.

Essa característica parece-nos uma grande chave para a compreensão do fenômeno da variação no campo léxico do bolchevismo. Segundo o constructo de Faulstich (2001), na categoria das variantes concorrentes, estas não ocupam o mesmo espaço, distribuindo-se de forma complementar em planos diferentes do discurso. Ora, essa particularidade já nos leva a eliminar toda a categoria das concorrentes de nossa análise, uma vez que observamos o uso de mais de uma variante no mesmo espaço discursivo, em relações de sinonímia.

A segunda categoria descrita por Faulstich (2001) é a de variantes coocorrentes, que é caracterizada pela sinonímia terminológica. Segundo a autora, "estas variantes têm por função fazer progredir o discurso e organizam, na mensagem, a coesão lexical" (FAULSTICH, 2001, p. 31). Essa categoria, em um primeiro momento, parece-nos condizente com o fenômeno terminológico que verificamos aqui. No entanto, uma vez que todo o campo léxico de bolchevismo é provindo do estrangeiro, precisamos tratar da categoria de variantes competitivas para compreendê-lo.

Faulstich (2001) esquematiza essa categoria da seguinte maneira: 
Figura 2 - Constructo teórico da variação em terminologia (modelo reduzido: variantes competitivas)

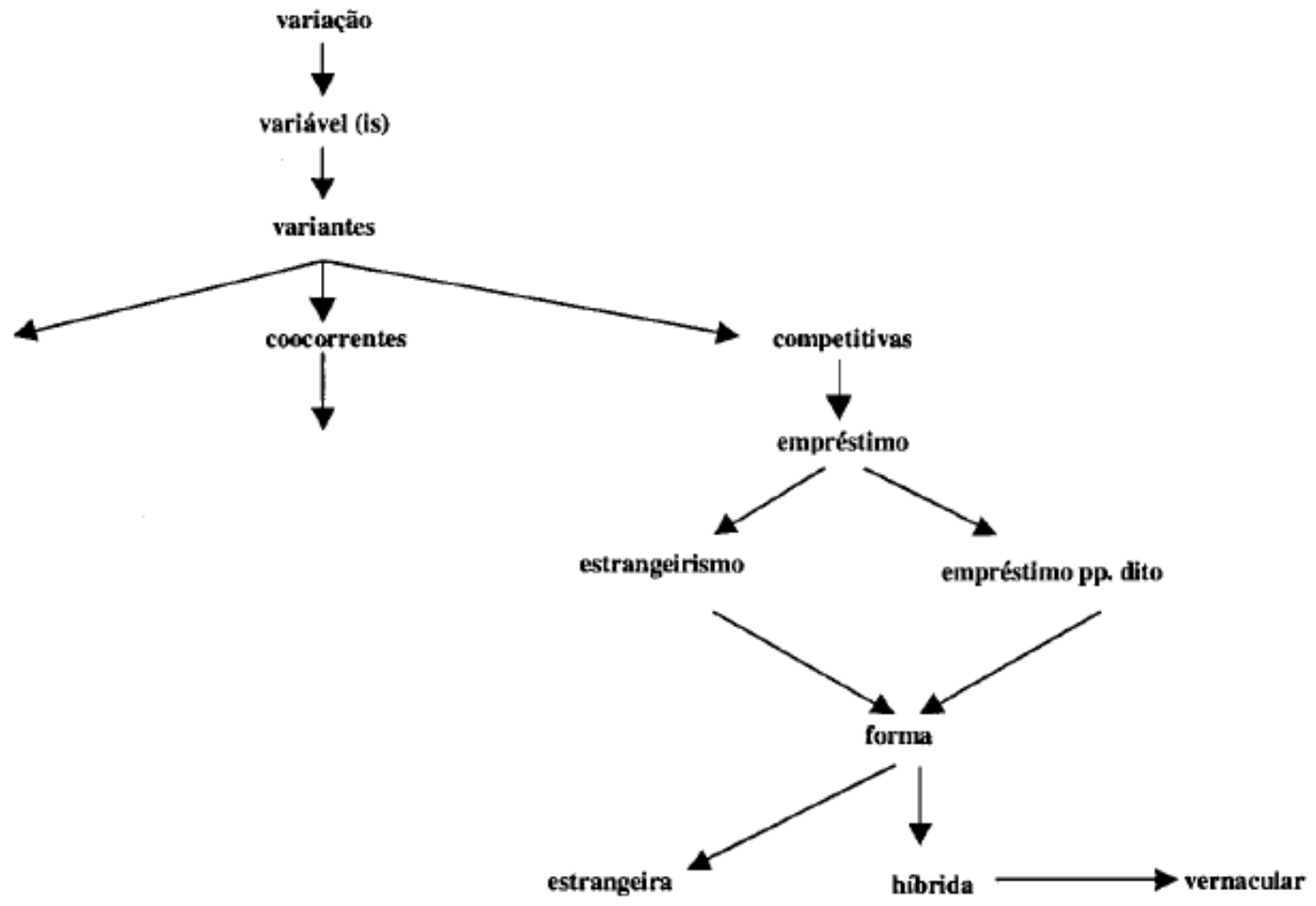

Fonte: Faulstich (2001, p. 33).

O constructo demonstra que as variantes competitivas são aquelas provindas de empréstimos de outras línguas. Os empréstimos podem evoluir, no interior da língua, de modo a permanecer sob a forma estrangeira, tornar-se um híbrido entre as duas línguas ou adquirir um caráter plenamente vernacular.

Entendemos que, em primeiro lugar, bolchevismo e suas variantes são termos que, de uma perspectiva linguística, chegaram ao Brasil de maneira indireta, uma vez que não havia um canal de comunicação entre Rússia-Brasil sem intermediários, o que significava também que não havia uma comunicação direta entre as línguas russa e portuguesa (ao menos no português brasileiro). Assim, se levarmos em consideração a afirmação de Edgard Leuenroth e Hélio Negro (apud MONIZ BANDEIRA; MELO; ANDRADE, 1980, p. 145, grifos dos autores) de que "Maximalismo, Bolcheviquismo, etc. são idiotismos que tiveram origem na tradução do idioma russo para o inglês e deste para o português", podemos considerar essa variantes como "empréstimos de segunda mão". 
Podemos entender que a dificuldade de fixação de um único conceito ao termo maximalismo foi motivada, talvez, por essa grande distância geográfica, linguística e cultural que separava os bolcheviques da Rússia dos brasileiros.

Avançando no constructo de Faulstich (2001), entendemos que os empréstimos ou estrangeirismos levam às formas estrangeiras e híbridas, que, por sua vez, motivam o surgimento de formas vernaculares. Nossa análise demonstra que maximalismo foi, no primeiro momento de veiculação das notícias da Revolução Russa no Brasil, a forma preferida pelas mídias, o que a popularizou entre diferentes extratos da população, fosse a intelectualidade ou o operariado. Compreendemos que maximalismo, maximismo, maximalista e maximista são formas híbridas, se pensarmos que seriam motivadas pelo inglês maximalist, tal qual indicou Houaiss (2009)23 e Edgard Leuenroth e Hélio Negro (apud MONIZ BANDEIRA; MELO; ANDRADE, 1980). Ainda assim, essas formas foram entendidas pelos brasileiros como formas plenamente vernaculares, haja vista a interpretação amplamente difundida de que maximalismo provinha da palavra máximo, de programa máximo, como apontaram Moniz Bandeira, Melo e Andrade (1980). A outra interpretação possível é que maximalista seria a tradução um pouco equivocada de maioria, ou bolchinstvó, raiz do termo bolchevizm no russo.

Ainda que maximalismo fosse a preferência inicial entre os jornais, verificamos diversas ocorrências de bolshevikismo, bolchevikismo, bolcheviquismo e bolchevismo. Através do constructo de Faulstich (2001), entendemos que estas são formas híbridas por excelência, que evidenciam o processo de assimilação da palavra estrangeira bolchevizm no português brasileiro em diferentes etapas. Parece-nos que bolshevikismo, bolchevikismo e bolcheviquismo foram formadas a partir de bolchevique ou bolchevik (большевик), о que explicaria as sílabas "ki” e “qui” no interior dos termos. Já bolchevista, bolshevista, bolcheviquista e bolshevikista apresentam o sufixo “-

${ }^{23}$ No entanto, não podemos confiar a priori nas informações contidas no Houaiss (2009): o verbete maximalismo apresentado no dicionário informa que a datação da palavra é de 1922, o que confirmamos não ser verdade com esta pesquisa. 
ista”, evidenciando mais possibilidades de formação híbrida advindas do processo de assimilação dos termos pela língua portuguesa.

Chegamos à conclusão, portanto, de que todas as variantes identificadas são do tipo competitivas híbridas, com a ressalva de que, a depender da interpretação etimológica de maximalismo e maximalista, estas possam ser consideradas plenamente vernaculares. Entendemos que todas as variantes representam estágios diferentes de assimilação dos termos estrangeiros no português brasileiro, sejam estes de origem russa, norte-americana, sejam, ainda, outra. Complementarmente, percebemos que alguns processos de assimilação foram gráficos, como em bolshevista/bolchevista, enquanto outros foram morfológicos, como em bolcheviquismo/bolchevismo.

Como apontou Bartz (2016), sob outro ponto de vista, a variação terminológica verificada no período de recepção da Revolução Russa no Brasil evidenciava as próprias aspirações dos militantes operários, que reelaboravam bastante as ideias comunistas, aproximando-as frequentemente das ideias anarquista libertárias em voga na época. Para o autor, essa época caracteriza-se por não possuir uma concepção de comunismo propriamente dita, o que possibilitava a identificação de anarquistas e sindicalistas à ideia comunista com mais flexibilidade:

Neste espaço de reelaboração de uma ideia, também se dá a possibilidade de sua apropriação de diversas formas, fazendo com que o bolchevismo russo se tornasse uma gama de diversos "maximalismos" locais. (BARTZ, 2016, p. 243)

No entanto, com a consolidação da União Soviética, e, posteriormente, com o surgimento da Terceira Internacional Comunista (1919) - que guiaria a intervenção dos partidos comunistas na política mundial - e do Partido Comunista Brasileiro (1922), definições mais precisas das ideias bolcheviques passaram a ser difundidas, o que fatalmente encerraria o período de criativa reelaboração em curso no Brasil:

A Plebe [6 de nov. 1920] traz um artigo sobre "O Maximalismo e os Anarquistas", mostrando a diferença entre as duas tendências. 
Acabava-se o noivado com a República dos Sovietes. Desfazia-se a confusão. À euforia dos primeiros momentos, em que todos os discípulos de Bakunin e Kropotkin se apresentavam como "maximalistas", sobreveio a necessidade das definições. (MONIZ BANDEIRA; MELO; ANDRADE, 1980, p. 259)

Esse momento, aparentemente, foi crucial para a eliminação das variantes que verificamos: maximalismo, bolshevikismo, etc. Com o tempo, foi surgindo mais coesão entre os comunistas brasileiros, o que culminou na fundação do Partido Comunista Brasileiro em 1922. Acreditamos que esse fator também influenciou na necessidade de fixação de um conceito uno e claro para o movimento político que fundou a União Soviética, e, com isso, o termo bolchevismo tornou-se o termo consagrado para tal conceito.

\section{Considerações finais}

Neste trabalho, pudemos constatar a multiplicidade de termos referentes ao bolchevismo que surgiram no Brasil em 1917-1920, momento em que, através das notícias vindas da Rússia, os brasileiros tomaram conhecimento do partido bolchevique e passaram a discutir o assunto da Revolução Russa. Dada as poucas fontes de informação disponíveis, observou-se uma grande confusão, mesmo entre os intelectuais, da própria definição do conceito de bolchevismo e maximalismo - que, vimos, foi relacionado tanto com o escritor Maxim Górki quanto ao suposto "programa máximo" que os bolcheviques adotavam. Para além disso, diversas representações gráficas eram utilizadas, contribuindo para a falta de univocidade dos termos.

O desenvolvimento histórico e conceitual do bolchevismo e do comunismo, a fundação de partidos comunistas que reivindicavam a história da Revolução Russa, como o PCB, no Brasil, e a atividade de propaganda encabeçada pela Terceira Internacional Comunista contribuíram, por sua vez, para a consolidação de definições menos ambíguas. Assim, desempenharam um papel na fixação e coesão dessa terminologia ao redor do mundo. 
Entendemos que diversos fatores são implicados no processo de variação no interior da língua: elementos sociais, fonológicos, entre tantos outros que não se esgotam de maneira nenhuma aqui. Dadas as limitações, esperamos, com este trabalho, ter evidenciado a importância dos estudos em Terminologia Diacrônica em interface com as Ciências Humanas para entender alguns dos aspectos linguísticos e sociais da nossa história. 


\section{Referências}

ALVES, Ieda Maria. Socioterminologie. Une approche sociolinguistique de la terminologie. Tradterm, São Paulo, n. 9, p. 229-232, dez. 2003.

AUGER, Pierre. Le phénomène de l'anglicisation de la langue forestière au Québec: essai de socioterminologie diachronique. In: CANDEL, Danielle; GAUDIN, François. (orgs.). Aspects diachroniques du vocabulaire. Mont-SaintAignan: Publications des Universités de Rouen et du Havre, 2006. p. 137-156.

BARBOSA, Ruy. Pelos soldados da Democracia. Bahia Illustrada, Rio de Janeiro, ano 2, n. 12, p. 11-12, 12 nov. 1918.

BARTZ, Frederico Duarte. O maximalismo como problema: circulação e apropriação da ideia de bolchevismo no movimento operário brasileiro durante os primeiros anos da Revolução Russa. Izquierdas, Santiago, n. 31, p. 235-248, dez. 2016.

BNDIGITAL. A Noite, Rio de Janeiro, a. 8, n. 2.529, p. 1, 28 dez. 1918a. Disponível em: http://memoria.bn.br/DocReader/docreader.aspx?bib=348 970_01\&pasta=ano\%20191\&pesq=bolshevikismo\&pagfis=14145. Acesso em: 4 ago. 2020.

BNDIGITAL. O Combate, São Paulo, a. 3, n. 8oo, p. 1, 7 jan. 1918b. Disponível em: http://memoria.bn.br/DocReader/DocReader.aspx?bib=830453\&pesq= maximista\&pasta=ano\%20191. Acesso em: $1^{0}$ mar. 2020.

BNDIGITAL. Correio Paulistano, São Paulo, n. 20.299, p. 4, 6 jan. 1920. Disponível em: http://memoria.bn.br/DocReader/DocReader.aspx?bib=0909 72_07\&pesq=bolshevista\&pasta $=$ ano\%20192. Acesso em: $1^{0}$ mar. 2020.

BNDIGITAL. Hemeroteca Digital Brasileira. 2020. Disponível em: http://bndigital.bn.gov.br/hemeroteca-digital/. Acesso em: 16 fev. 2020.

CANDEL, Danielle; GAUDIN, François. (orgs.). Aspects diachroniques du vocabulaire. Mont-Saint-Aignan: Publications des Universités de Rouen et du Havre, 2006.

DURY, Pascaline; PICTON, Aurélie. Terminologie et diachronie: vers une réconciliation théorique et méthodologique? Revue Française de Linguistique Appliquée, Paris, v. 14, n. 2, p. 31-41, 2009.

DURY, Pascaline; DROUIN, Patrick. L'obsolescence des termes en langues de spécialité: une étude semi-automatique de la "nécrologie" en corpus 
informatisés, appliquée au domaine de l'écologie. Aarhus: Aarhus University, 2010.

FAULSTICH, Enilde. Principes formels et fonctionnels de la variation en terminologie. Terminology, Amsterdam, v. 5, n. 1, p. 93-106, 1998.

FAULSTICH, Enilde. Aspectos de Terminologia geral e Terminologia variacionista. TradTerm, São Paulo, n. 7, p. 11-40, 2001.

FINATTO, Maria José Bocorny. Terminografia brasileira no final do século XIX: contraponto entre domínios emergentes e consolidados. In: KRIEGER, Maria da Graça; MACIEL, Anna Maria Becker (orgs.). Temas de terminologia. São Paulo; Porto Alegre: Ed. UFRGS; Humanitas USP, 2001. p. 197-213.

GAUDIN, François. Socioterminologie : du signe au sens, construction d'un champ. Meta, Montréal, v. 38, n. 2, p. 293-301, 1993.

GAUDIN, François. Quelques mots sur la socioterminologie. Cahiers du RIFAL, Bruxelas, n. 26, p. 26-35, 2007.

HERMANS, Ad. Terminologie diachronique. Actes du colloque organisé à Bruxelles les 25 et 26 mars 1988. Meta, Montréal, v. 36, n. 4, p. 678-680, 1991.

HOUAISS ELETRÔNICO. Maximalista. São Paulo: Objetiva, 2009. Disponível em: https://houaiss.uol.com.br/corporativo/apps/uol_www/v5-4/html/index. php\#o. Acesso em: 8 ago. 2020.

KRIEGER, Maria da Graça; MACIEL, Anna Maria Becker (orgs.). Temas de terminologia. São Paulo; Porto Alegre: Ed. UFRGS; Humanitas USP, 2001.

KRIEGER, Maria da Graça. Terminografia médica no Brasil no século XIX. In: KRIEGER, Maria da Graça; MACIEL, Anna Maria Becker (orgs.). Temas de terminologia. São Paulo; Porto Alegre: Ed. UFRGS; Humanitas USP, 2001. p. 172-181.

LONTRA DA CONCEIÇÃO, Fabiana Zogbi. O discurso leninista (1902-1918): levantamento terminológico. Monografia (Graduação em Letras) - Instituto de Letras, Universidade Federal do Rio Grande do Sul, Porto Alegre, 2019.

MACEDO, Cristian Cláudio Quinteiro. A arte da tradução: um breve exercício de terminologia diacrônica. Cadernos do IL, Porto Alegre, n. 59, p. 255-270, out. 2019.

MACIEL, Anna Maria Becker. Estrutura e funcionamento dos dicionários jurídicos no Brasil do século XIX. In: KRIEGER, Maria da Graça; MACIEL, Anna Maria Becker (orgs.). Temas de terminologia. São Paulo; Porto Alegre: Ed. UFRGS; Humanitas USP, 2001. p. 182-196. 
MALDONADO, Luccas Eduardo. O Ano Vermelho: entre 50 e 100 anos. Lutas Sociais, São Paulo, v. 21, n. 38, p. 208-211, 2017.

MARENGO, Sandro Márcio Drumond Alves. Variações terminológicas e diacronia: estudo léxico-social de documentos manuscritos militares dos séculos XVIII e XIX. Tese (Doutorado em Letras) - Faculdade de Letras, Universidade Federal de Minas Gerais, Belo Horizonte, 2016.

MONIZ BANDEIRA, Luiz Alberto; MELO, Clóvis; ANDRADE, Aristélio Travassos. O Ano Vermelho: a revolução russa e seus reflexos no Brasil. 2. ed. São Paulo: Brasiliense, 1980.

REIS FILHO, Daniel Aarão. A revolução de mudou o mundo: Rússia, 1917. São Paulo: Companhia das Letras, 2017.

SODRÉ, Nelson Wernerck. Uma contribuição importante. In: MONIZ BANDEIRA, Luiz Alberto; MELO, Clóvis; ANDRADE, Aristélio Travassos. $O$ Ano Vermelho: a revolução russa e seus reflexos no Brasil. 2. ed. São Paulo: Brasiliense, 1980. p. 9-11.

SOUZA, Ivan Pereira de. Do engenho à usina: estudo diacrônico da terminologia do açúcar. Dissertação (Mestrado em Letras) - Faculdade de Filosofia, Letras e Ciências Humanas, Universidade de São Paulo, São Paulo, 2007.

VOLÓCHINOV, "Valentin”. A palavra na vida e a palavra na poesia. São Paulo: Editora 34, 2019.

WEILL, Claudie. À propos du terme "bolchemisque". Cahiers du monde russe et soviétique, v. 16, n. 3-4, p. 353-263, jul./dez. 1975.

Artigo recebido em 15 de maio de 2020 e aceito em 26 de julho de 2020. 